\title{
Mirror Syndrome: A Rare Presentation with a Trisomy 21 Fetus
}

\author{
Prasanga DPGGM, Dias TD, Palihawadena TS, Gunathilaka SNMPK, Herath HMR, Wasalathilaka CD
}

\section{INTRODUCTION}

Maternal mirror syndrome or Ballantyne syndrome is a rare consequence of severe fetal hydrops of either immune or non-immune etiology. True incidence of mirror syndrome is unknown as very few cases are described in the literature ${ }^{1}$. It is characterized by fetal or placental hydrops with maternal oedema, mild hypertension, albuminuria, aneamia, ascites \& pleural / pericardial effusion. It was first described by John W Ballantyne in 1892, thus acquiring its name. It is also called mirror syndrome since the maternal condition mirrors the fetal pathology.

Pathogenesis of mirror syndrome has not yet been completely explained. The etiology for fetal hydrops could range from any of Obstetrics problems such as immunological disorders including Rhesus isoimmunisation or fetal infections, metabolic disorders, structural fetal anomalies (cardiac structural anomalies) or functional cardiac abnormalities such as arrhythmias ${ }^{2,3,4}$. The fetal outcome in mirror syndrome is generally poor and it is also associated with significant maternal morbidity. There are case reports of improvement in maternal condition with successful treatment of fetal hydrops. Such improvement has also been noted with spontaneous resolution of fetal hydrops resulted from a parvovirus B19 infection ${ }^{2}$. We report a case of mirror syndrome following a trisomic fetus to highlight importance of considering this in the

Professorial Gynaecology Unit, Department of Obstetrics \& Gynaecology, University of Kelaniya.

Correspondence: Dr. T. Dias

E-mail: thiran_dias@yahoo.com

Competing interests: None diagnostic work up of a patient with significant oedema during pregnancy.

\section{CASE REPORT}

A 36 years old woman in her third pregnancy presented with a history of mild vaginal bleeding at 25 weeks of gestation. Her first pregnancy has been uncomplicated resulting in a term vaginal delivery. The second pregnancy has been complicated with pregnancy-induced hypertension requiring an emergency cesarean section at 38 weeks due to placental abruption. She had booked at seven weeks in present pregnancy. Her booking blood pressure has been $110 / 70 \mathrm{mmHg}$ and the laboratory investigations have been normal. She was of the A positive blood group and her pregnancy up to this presentation has been uncomplicated.

Generalized body swelling was noted on admission and there was trace amounts protein in her urine. The blood pressure (BP) was within normal limits $(120 / 80 \mathrm{Hgmm})$. an ultrasound scan (USS) for fetal wellbeing revealed pericardial and pleural effusions in the fetus with the presence of ascites and soft tissue swelling, confirming a diagnosis of fetal hydrops. Maternal ascites was also noted at ultrasound scan.

Unexpected antibodies were negative in maternal blood. There was no parental ABO incompatibility. Maternal work-up for diabetes, preeclampsia, cardiac, liver and renal dysfunction was performed and the hematological and biochemistry investigations were all normal. She underwent an uncomplicated amniocentesis to check for any possible chromosomal aneuploidies.

The maternal oedema increased over the next few days with no change in the blood pressure values and the severity of proteinuria. On the fifth

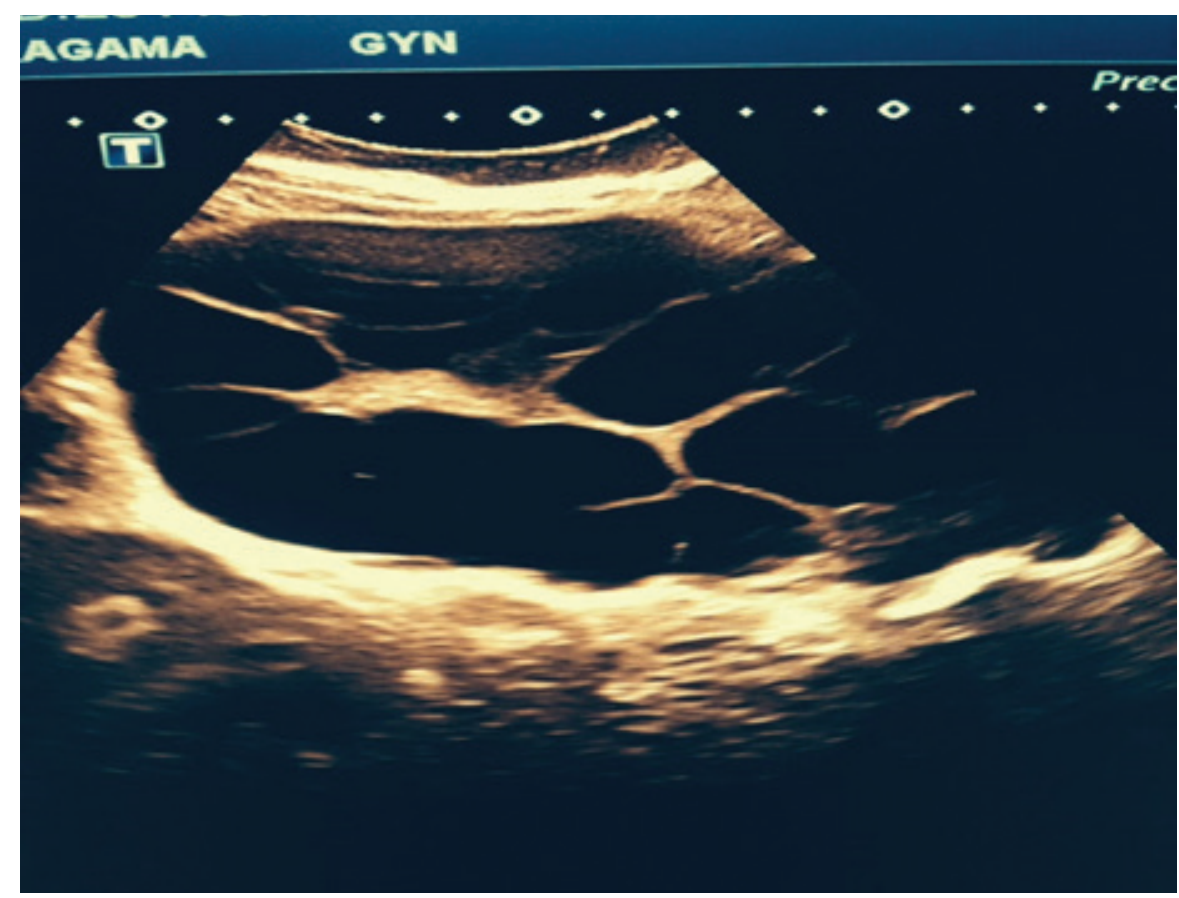

Figure 1: Ultrasound appearance of the ovary with large theca luteal cysts 
day following admission fetal demise was noted and labour was induced. There were no identifiable dismorphic features. A female stillborn with significant hydrops weighing 678 grams was delivered vaginally. Post-mortem of the fetus revealed pericardial and pleural effusions with ascites and an atrophic brain while other internal organs were normal. Maternal oedema gradually improved following delivery of the fetus. She had a speedy recovery and was sent home 48 hours after delivery. Amniotic fluid chromosomal analysis from the amniocentesis revealed Trisomy 21. Two weeks in to the pueperium, she presented with hypertension and large bilateral theca luteal cysts were detected on ultrasound scan. Antihypertensive treatment was commenced and she was referred to the medical clinic for further follow up.

\section{DISCUSSION}

Mirror syndrome is often associated with severe fetal hydrops. The syndrome classically includes massive anasarca, proteinuria, and mild hypertension in the presence of fetal hydrops. Careful evaluation is mandatory to differentiate from preeclampsia since there is considerable overlap in the clinical presentation. The morbidity could be more severe in mirror syndrome than with preeclampsia. The pathogenesis of mirror syndrome has not been described, though placental origin seems likely. Some suggest placental ischemia in the development of preeclampsia, and in mirror syndrome, this may develop secondary to the placental oedema ${ }^{5}$. Further research on serum markers of placental dysfunction may help in understanding the underlying etiology of mirror syndrome. Untreated, mirror syndrome could lead to significant maternal and fetal morbidity and mortality. Therefore, it should be considered in the differential diagnosis of unexplained maternal oedema in pregnancy. Timely diagnosis and appropriate interventions may improve maternal condition in most instances while the fetal and outcome may also be improved in few instances.

\section{REFERENCES}

1. Vidaeff A.C, Pschirrer E.R, Mastrobattista J.M, Gilstrap L.C, . Ramin S.M. Mirror syndrome: a case report, J Reprod Med. 2002;47(9):770-774

2. Goeden A.M, Worthington D. Spontaneous resolution of mirror syndrome, Obstet and Gynecol. 2005;106(5):1183-1186.

3. Carbillon L, Oury J.F, Guerin J.M, Azancot A, Blot P. Clinical biological features of Ballantyne syndrome and the role of placental hydrops, Obstet Gynecol Surv. 1997;52(5):310-314, 1997.

4. Midgley D.Y, Harding K. The mirror syndrome. Eur J Obstet Gynecol Reprod Biol. 2000;88(2):201-2.

5. Rana S, Venkatesha S, DePaepe M, Chien E.K, Paglia M, Karumanchi S.A. Cytomegalovirus-induced Mirror syndrome associated with elevated levels of circulating antiangiogenic factors. Obstet and Gynecol. 2007;109(2):549552. 